\title{
DEVELOPMENTAL DIDACTICS FOR PROFESSIONAL SKILLS AND UNIVERSITY EDUCATION
}

\author{
Quiroz AGT* \\ National University of Callao, Callao, Perú
}

\begin{abstract}
The objective of the article was to determine the effect of developer didactics in university education, related to teaching, learning and training of graduate professionals, strengthening their identity and empathy with social reality. University education must prepare citizens, its objective is to prepare, train and educate. In this process, skills, abilities, capacities and competencies are acquired to solve society's problems through research, scientific knowledge, which is used to solve them. The developer didactics allowed to overcome the difficulties of the educational teaching process, which was based on constructivism that allowed affirming learning. The methods of learning based on problems and cooperative were applied. The sample consisted of 121 undergraduate students, distributed in 3 time groups. The quality of the model for the proposed learningteaching process allowed the achievement of significant knowledge. The evaluation was participatory and innovative in nature, not directive; the contents were evaluated at the level of knowledge, procedures and attitudes, within the framework of the professional profile and the exercise of their professional career. The research showed that through the application of developer didactics, general, professional and specialized competences were significantly promoted in students. This process was materialized in an evaluation of a participatory nature, of a continuous nature in the subject, being a significant achievement, with an average of more than 17. Therefore, the approach based on the development didactics in a curriculum by competencies, is highly significant and representative in the three investigated samples.
\end{abstract}

Keywords: Developer didactics, socioformative, professional competences, pedagogicaldidactic method, educational teaching process, education

\section{Introduction}

In recent decades, university education has faced the challenge of training professionals who respond to social needs effectively and efficiently. Evidence of insufficient linear rationality to current and future need; the alternative to overcome the problem is to propose an epistemological rupture to the educational conception and to deepen critical thinking aligned with diversity. To achieve this, it is necessary to criticize their educational practice, establish innovative pedagogical proposals for a significant change to the learning-teaching process.

According to Zabalza, (2007), university education is complex, it is not always the center of attention, by itself, it is a problem. There are three teaching approaches: empirical, artisanal, and intuitive in nature to teaching practice. Professional approach, with a professional profile, that is, teaching requires preparation to exercise it. Specialized theoretical approach, the teacher is an expert specialist. 
Hinge teachers, knowledge intermediaries, are not required; they must exercise research, teaching and social responsibility; that is, research-teach-project. The university must prioritize environmental problems, select problems, investigate and solve them, returning scientific knowledge. The instrument that makes this practice viable is the developer didactics, which will be useful to solve the needs of the country, region and locality.

Also, Álvarez (2003), affirms that teaching implies dynamizing activities in different settings, being necessary the epistemological rupture of teaching-learning, there educational actors interact, that is, the university must respond to social needs.

For Seville (2005), the educational reality of the $21^{\text {st }}$ century is evident in new social, educational, information, and changing society contexts. The university must respond to the needs of teachers and students. There is a diverse and multicultural reality, therefore university education must promote interculturality with inclusion, with the developer teaching that is capable of identifying problems.

The educational process models the personal and social personality, if it promotes scientific culture, then it transforms the tradition, generating social and cultural impact. In this regard, Bermeosolo (2016) affirms that, through learning, changes in behavior are observed permanently, as a consequence of institutional and social practice.

In this context, the developer didactics requires integrated social and educational institutions, a pedagogy and scientific didactics is optimal to solve curricular and social problems. According to Medina (2013) reflecting on university learning and teaching, the university is experiencing a process of reconstruction of historical identity of vertiginous internal and external changes, complex educational, social, cultural and ideological changes occur, simultaneously forming and solving problems that emerge from the society and returns solutions to transform it. The basis of this action is the curricular, pedagogical and didactic system.

Also, Moral (2015), suggests specifying the didactics, starting with the professional training of the teacher, and challenging educational challenges. Díaz (2016), says that these activities solve with the curriculum, structure knowledge in the disciplinary framework, determine appropriate content, what to teach, their interrelationships, etc. The curriculum defines what it should, when and how to teach, what to evaluate, to develop; abandoning mentalism, behaviorism and other practices that hinder the curriculum with a developer approach.

In this logic, the curriculum is related to the micro curriculum that specifies the teaching-educational process through the subject, syllable, unit and didactic content and its developer method. According to Posner (2005), the curriculum is related to the educational purpose, it must include diversity, build professional skills and competencies.

The curriculum in a developer framework optimizes the teaching-learning process. In this logic, the research focused on the exercise of developer didactics, to generate skills at a general, professional and specialized level. 


\section{Didactic Developer}

The developer didactics bases the understanding of social reality. It implies scientific vision of university professionals, its application refers to a counter-epistemology for university education at a biological, social and cultural level. Cultures, with different views of the world, with different needs, demand for professionals who know that reality. It implies an educational change. For Tenti (2010), all educational change occurs at the macro level, related to the evolution of social forces; also political and administrative. The work of teachers and educational centers within the framework of a culture; It will consist of knowing, interpreting, identifying relevant social problems; solving for well-being and respecting the environment in a balanced bioculturality. Developer didactics solves this problem, evaluating the relationship between education, pedagogy and didactics.

According to Sarramona (2012), it is a complex holistic process, it benefits or affects the individual and society. As a sociocultural exercise, it humanizes and models the human being. As a social fact, it is dynamic, it integrates, it grants values, it is the basis of culture; Also, permanent, unfinished and complex. In the case of university education, Zabalza (2007), highlights that the university is far from the social environment. In a heterogeneous society, there is a demand for the solution of its problems. If there are culturally heterogeneous students, indifference to teacher training, precarious financial resources and poor university management, these problems will not be solved.

In the context of pedagogy, Álvarez de Sayas (2005), argues that an epistemology of transit is needed in university education. If social development allowed production to advance, then pedagogy must contribute to instructing, training and educating the student, it is a problem that must be solved through education.

In the field of didactics, the same author, Álvarez de Sayas (2003), affirms the link between the teaching-learning process, which is energized by teachers and students, each one develops activities of the curriculum and micro-curriculum. If you educate by teaching and learning, your action is directed to your object of study, consisting of the contents, that is, the scientific culture selected in a subject. In every didactic process, two systems are identified, the educational teaching process and teachinglearning; pedagogy and didactics. Pedagogy forms the individual, social subject, and didactics instructs him, and education forms him. With the educational teaching process, it systematizes educational subsystems. According to Sayas, this process guides the problem, object, objective, content, method, form, medium and evaluation. Educational actors intervene, who are trained by order of society.

\section{Educational teaching process}

In the university, to meet the educational goals, both the teacher and the student, within the framework of a scientific education, social problems are solved through relevant curricular content. This compliance is based on:

First, that in every society there are urgent needs that must be resolved, therefore, these facts are a curricular objective, dissatisfaction or absence of something is identified. It is the starting point of the curricular contents and the methods to solve them. If the problem identified determines the objective, 
content and pedagogical didactic method, then, through epistemology, a certain problem is classified. It is necessary to apply a method, technique and educational pedagogical strategy to solve it.

For this reason, it is a task that by means of the developer didactics, competences must be granted to solve the problems of the university environment. Its task is binding on the educational and social system, it must prepare professionals with sufficient skills to solve them. Therefore, it is necessary to design an innovative curriculum that provides general, professional and specialized abilities, skills, abilities and competencies. Likewise, promoting reflection from teaching, Biggs (2005), affirms that a reflective attitude is the foundation of education, it generates critical thinking. Through this action, educational actors commit to their reality where they live.

Through developing didactics, he masters the content, on three levels. First, he internalizes the content and knows his cultural environment, he has the ability to interpret his reality. Second, with the content, processes and is able to propose the necessary changes in the social environment. Third, social change is possible when you make qualitative and quantitative contributions to social development and transformation. That is the sphere of action of the developer didactics, being an agent of change and affirmation of the university identity and of society.

This process is fulfilled with an innovative university teaching, in this sense Zabalza (2012), states that the university must revalue its presence in society, if it does not comply, establish a reengineering of the curriculum, teaching practice and educational practice, looking for the quality of university training on an ongoing basis. Developing didactics should be fostered in an integral way, promoting the inclusive curriculum and micro-curriculum, with current educational theories and methods, supporting a scientific didactics, with significant learning.

If the didactics is developmental within the framework of a scientific, humanistic pedagogy, committed to reality, then abilities, capacities, skills and competences are generated; in addition to values and attitudes, achieving professional training integrated into the environment, society and culture. An education for society, not for itself, in this case Brígido (2006), affirms that the approach implies that individuals are socialized with the group, culture and the institutions that govern it, it is a space where the development didactics for social change.

If there is an educational reality with inequities in the educational field, and in a diversity, education becomes authoritarian, homogenizing and excluding the majority. The problem is compounded if education is of poor quality and becomes an economic good subject to the laws of the market. The complication will be even greater if there is economic, social, cultural, political and ideological exclusion. An answer in this complex reality would be the promotion of inclusion and successful university culture, in this context, Molina (2014), suggests reviewing the educational epistemology of the University of Teachers, students, the curriculum, its management and administration. If the teaching practice passes through a philosophical conception dominated by empiricism and inductivism, then it is necessary to understand the object of education. Three approaches to science are identified, including methodology. The scientist approach, seeks generalization of results in a quantitative approach. The interpretive is based on qualitative methodologies. Critical approach, focused on research to transform that integrates the quantitative and qualitative, with a developer approach. Being necessary to analyze the teaching practice and management in a context of cultural diversity, the university and society, promoting academic goals linked to reality; promotion of 
personality, communication with their culture, strengthening their identity, a pertinent ecology in the classroom and finally seeking the connection with educational institutions and in addition to including it socially.

Consequently, didactics is a developer and must be specified in a scientific, intercultural humanistic pedagogy, committed to its reality, being necessary, according to Manayay (2011), to base on which the subject, curriculum plan, the problem that specifies the why, its purpose, content, method and evaluation of the subject, be it a process that is specified in the learning session. The training of professionals within the framework of developer didactics is a consequence of the materialization of the curriculum.

\section{Methodological Design}

In the investigated problem, the mixed methodology was used. The objective was to demonstrate the importance of developer didactics in the formation of professional competences of university students. It is a descriptive, transversal investigation in the compilation of information and longitudinal in the analysis of the qualitative and quantitative development of the problem. It was based on the constructivist approach and learning methods based on PBL and cooperative problems. The study population was students from the Faculty of Economic Sciences, National University of Callao who attended learning sessions on the subjects of Research Methodology and Thesis I. Sample of 121 students.

The curriculum and micro-curriculum were investigated, Velásquez (2005), specifies that the university curriculum leads to obtaining an academic degree or professional title, specifies educational objectives within the framework of the educational teaching process to form meaningful and transformative competencies, generating breaks in learning. An epistemology of learning based on active, internalized processes, transforming information into new situations is necessary.

The student assumes control of their learning, is trained to perform efficiently in their professional practice and in society applies knowledge to real situations. The teacher is a facilitator, guides the construction of knowledge of his students in the developer framework. For Tobón (2015), constructivism must develop the curriculum, a collaborative process, rebuild to transform. In another context, Tobón (2012), conceptualizes the socioformative approach to understand a holistic totality of the human being. The curriculum must be adapted for human training, based on didactics that promote competencies, valuing the training process.

In the context of the methods used, Escribano (2010) affirms that traditional education is based on a process of intensive learning sessions that respond to an established curricular plan, making it difficult to manage. On the other hand, if we apply the methods of problem-based learning and cooperative in small groups, students measure knowledge as a problem, identify needs and seek information to solve the problem. Along these lines, Bouden (2012) considers that problem-based and cooperative learning allows students to observe what they are going to learn. Learning is in a real context. Also, Biggs (2005), considers that the starting point of learning is the problem, which the student must solve in a curricular framework. Its application has advantages in university education because it motivates, generates scientific competencies, processes information, strengthens critical thinking with breaks. In the development framework of the practice, the process was considered in the context of a training 
project. In this regard, Tobón (2014), establishes that it should be oriented to solve problems in the social context of the university, where knowledge, competencies, activities are articulated to achieve specific products, that is, to solve the problem of knowledge, based on learning meaningful, collaboration and metacognition.

Also in the methodological context, group dynamics, as stated by Delgado (2014), its application made it possible to systematize and organize the learning process, encouraged the participation and transfer of learning between students, promoting dynamic, ecologically pleasant learning, and facilitating the evaluation. By the way, Acaso (2018), affirms that the methodological design contextualizes an invisible pedagogy, where reality is the curriculum, with a set of meanings that are directed to the recipients, in a linguistic context, in this case, the educational teaching process, it was processed in 6 phases:

Phase 1. - Selection of the subject to be developed for the practice process.

Phase II. - Identify the Why of the subject

Phase III. - Identify the purpose of the subject.

Phase IV. - Identification of the what of the subject, the content to be investigated

Phase V. - Identification of the how of the subject, the method.

Phase VI. - Identification, the what of the subject, participatory and non-directive evaluation.

\section{Development of the Phases}

Development of 15 sessions at a theoretical and practical level, research methodology subjects, thesis I, 3 time groups $02 \mathrm{E}, 12 \mathrm{E}$ and $13 \mathrm{E}$, in the process:

Initial diagnosis.- Overcome the traditional teaching based on mentalism and behaviorism. There is a high disapproval rate that affects the training of professional skills. What is the alternative to solve this educational problem?

The answer, establish a curricular theoretical and methodological source within the framework of the developer didactics. The model, based on the constructivist approach, of the educational teaching process and establishment of the problem-based and cooperative learning method was systematized. It includes the design of the learning session, with activities adjusted to the model.

Development of the practice.- Evaluation of 15 sessions of learning, theory and practice.

-Theory session, internalizes the developer content, acquires the ability to apply to cases of the environment. Instruments, application sheets, systematization and rubrics. Didactic strategies, to investigate previous processes, questions; others that promote understanding by organizing information, diagrams, cognitive maps, summary, synthesis, essay; group; and active methodology. 
-Practical session, apply learning to problems in the environment, was specified in conceptual, procedural and attitudinal evaluation of each session. A high level of learning was achieved by the participants of the subjects evaluated.

\section{Results}

The research is focused on the development of the individual and group educational teacher, in the methodological framework, in problem-based and cooperative learning.

Evaluation of Time Group 02E, systematized in the figure 1:

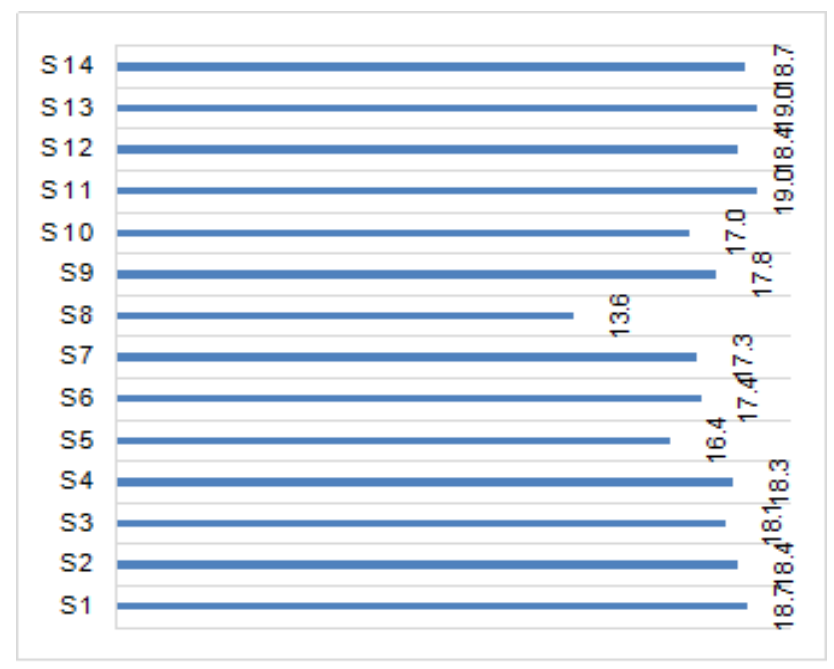

Figure 1: Average evaluation trend per week, time group 02E. Final average 17,7.

It is observed, evaluation average, in week $1,18.7$; week 2 , 18.4; week $3,18.1$; week $4,18.3$; week 5 , 16.4; week 6, 17.4; week 7, 17.3; week 8, 13.6; week 9, 17.8; week 10, 17.0; week 11, 19.0; week 12, 18.4; week 13, 19.0; week 14, 18,7. Final average 17. It. Was shown that the developer didactics was effective in achieving professional skills in students, as shown in figure 1.

Evaluation, time group 12E, systematized in figure 2:

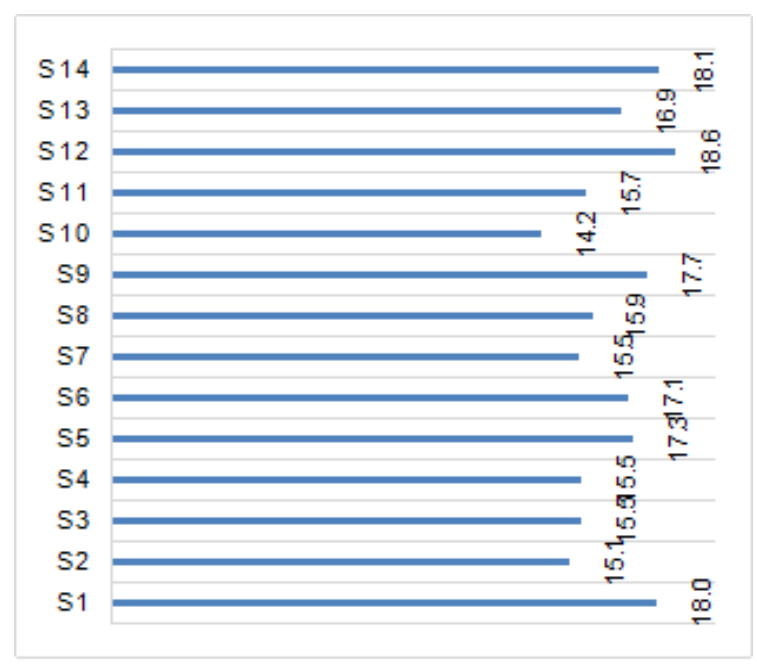


Figure 2: Average evaluation trend per week, time group 12E. Final average 16, 5.

It is observed, the average of evaluation in week1, 18.0; week 2, 15.1; week 3, 15.5; week 4, 15.5; week $5,17.3$; week $6,17.1$; week $7,15.5$; week $8,15.9$; week $9,17.7$; week 10, 14.2; week 11, 15.7; week 12, 18.6; week 13, 16.9; week 14, 18.1. Final average 16.5. It.

Was shown that effective development didactics in the achievement of professional competencies, figure 2 .

Evaluation of time group 13E, systematized in figure 3.

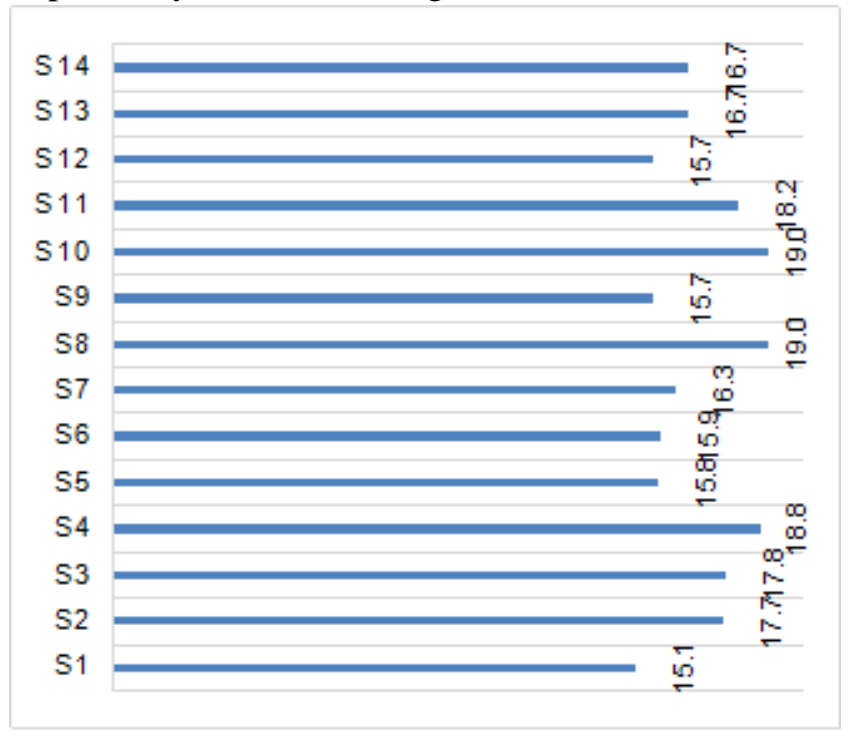

Figure 3: Average evaluation trend per week, time group 13E. Final average 17, 0.

It is observed, the average of evaluation in week1, 15,1; week 2, 17.7; week 3, 17.8; week 4, 18.8; week 5, 15.8; week 6, 15.9; week 7, 17.3; week 8, 19.0 week 9, 15.7; week 10, 19.0; week 11, 18.2; week 12, 15.7; week 13, 16.7; week 14, 16.7. Final average 17.0. It was shown that effective development didactics in the achievement of professional competencies, figure 3 .

\section{Conclusions}

It was shown that the constructivist approach, applying the method of problem-based and cooperative learning in the context of the developmental didactics of the competency curriculum, is statistically significant. The measure of central tendency showed that the hourly groups $02 \mathrm{E}, 12 \mathrm{E}$, and $13 \mathrm{E}$ of the research methodology course and thesis I, is significant in more than 17.

In the Faculty of Economic Sciences of the National University of Callao, the curriculum by competences is being implemented. It was shown that the model of developer didactics, personalized and group evaluation, contributed to forming professional capacities and competencies in the investigated students.

The pedagogical proposal of the developer didactics, designed in the subject, syllabus, unit, learning session and participatory evaluation, is pertinent. The statistical results showed significant indices in more than 17 of the personalized and group evaluation in the investigated students. 
The developer didactic pedagogical model is pertinent and timely, according to the quantitative data of the results, its application allowed to consolidate professional competences in the investigated students.

\section{Recommendations}

Continuous training in pedagogy and didactics is recommended for teachers of the Faculty of Economic Sciences, National University of Callao, in order to guarantee the correct administration of the university curriculum.

It is recommended to implement the developer didactics model in the university curriculum of the National University of Callao, to guarantee professional competences of university students.

It is recommended to plan and execute a curriculum with a developer didactics profile to improve the quality of professional training for university students.

\section{References}

Acaso, M. (2018). Invisible pedagogies. The classroom space as a discourse. Madrid, Espain: Catarata Publishing House.

Álvarez de Sayas C. y Gonzalez Aguedo, E.M. (2003). General didactic lessons. Colombia: Editorial Teaching Teaching.

Álvarez de Sayas, C. (2005). Pedagogy, a model of man formation. Lambayeque, Peru: Editorial Faculty of Historical Social Sciences and Education, Pedro Ruiz Gallo National University.

Bermeosolo Bertrán, J. (2016), How human beings learn, a psychopedagogical approach. Chile: Editorial Catholic University of Chile.

Biggs, J. (2005). Quality of university learning. Madrid, Spain: Editorial Narcea.

Bowden J. y Marton F. (2012). The University, a space for learning beyond quality and competition. Madrid, Spain: Editorial Narcea.

Brigido, A. M. (2006). Sociology of Education. Argentina: Editorial Brujas.

Díaz-Barriga, A. F. et.al (2016). Curriculum design methodology for higher education. Mexico: Editorial Trillas.

Delgado, K. (2014). Group dynamics, educational applications. Lima, Peru: Editorial San Marcos.

Escribano, A. y Del Valle, A. (2010). Problem-based learning. Madrid, Spain: Editorial Narcea.

María, A. (2012). Invisible pedagogies. Madrid, Spain: Editorial Los Libros de la Catarata.

Manayay Tafur, M. (2011). Module II, Microcurriculum. Curricular plan of the course. Lambayeque, Peru: Editorial Pedro Ruiz Gallo National University. Second Specialty in University Curriculum and Didactics.

Medina Moya, J. L. (2013). Teaching and learning in higher education. Spain: Editorial Síntesis.

Molina Andrade, A. (2014). Teachers' conceptions about the phenomenon of cultural diversity and its implications in science teaching. Colombia: Editorial CAIDE.

Moral Santaella, C. Et.al (2015). Didactics, theory and practice of teaching. Spain: Editorial Pirámide.

Posner, G. (2005). Curriculum analysis. Mexico: Editorial Mc Graw Hill.

Sarramona, J. (2012). Theory of education. Barcelona, Spain: Editorial Ariel. 
Sevillano García, M. L. (2005). Didactics in the XXI Century. Axes in quality learning and teaching. Spain: Editorial Mc Graw Hill.

Tenti Fanfani, E. et.al (2010). The teaching profession. Argentina: Editorial Siglo XXI. S.A.

Tobón, S. (2012). Comprehensive training and skills, complex thinking, curriculum, didactics and evaluation. Colombia: Editorial Ecoe Ediciones.

Tobón, S. (2014). Training projects, theory and methodology. Mexico: Editorial Pearson.

Tobón, S. (2015). Curriculum management methodology, a socioformative perspective. Mexico: Editorial Trillas.

Velázquez Fernández, A. y Rey, N. (2005). Curriculum management and university education. Lima, Peru: Editorial University of San Martin de Porres.

Zabalza, A. (2007). University teaching. The stage and its protagonists. Madrid, Spain: Editorial Narcea.

Zabalza Beraza, M. y Zabalza Ceideiriña, M.A. (2012). Planning of teaching at the university. Preparation of teaching guides for the subjects. Madrid, Spain: Editorial Narcea.

Zabalza Miguel A. (2007). Teaching skills of university teaching staff, quality and professional development. Madrid, Spain: Editorial Narcea. 